\title{
A STRATEGY FOR THE DEVELOPMENT OF THE HUMAN RESOURCES OF THE SA DEFENCE FORCE FOR THE YEAR 2000
}

Rear-Admiral R. Eberlein*

\section{INTRODUCTION}

The SA Defence Force (SADF), in common with other organisations and people in the Republic, is experiencing considerable upheaval and change in the four acknowledged power bases: socio-political; economic; technological and military. This upheaval and change is highly visible to some in the organisation, less visible to others and to some, merely perceived as discomfort or uncertainty in what is usually seen as a very stable organisation. Members of the SADF who are involved daily with long-range planning of, for example, manpower requirements or the development of equipment and material are more likely to perceive the effects of change from their lofty positions than are their colleagues faced with the day-to-day battle for survival.

The upheaval and change manifests itself in a number of ways which are sometimes not perceived as being caused by change, unless one knows where to look and what to look for. For instance, we in the personnel field are aware of the problem of labour turnover which manifests itself as a lack of retention of key personnel. Perhaps if we examined this problem in terms of change, particularly a changing culture, we might find solutions different from those usually applied.

We are aware of some of these changes, their causes and probable effects but not of others. What is not commonly realised though, is that similar changes are occurring in many different countries around the world, and that while no comparison can be drawn between changes occurring in particular countries, this phenomenon of change itself has several common characteristics.

It has been realised that these changes impinge upon and will impinge upon the ability of the personnel in the Defence Force to perform their tasks effectively, and consequently upon the ability of the Defence Force as an organisation to meet its primary and secondary objectives, un- less steps are taken to counter or to manage the effects of change.

In this paper an attempt will be made to present a plan of action which would enable the SA Defence Force (SADF) to achieve optimum development and utilisation of its human resources in the year 2000 .

\section{THE APPARENT PROBLEM}

As a point of departure, the apparent problem (the null hypothesis) can be posed in the form of a question:

"Will the personnel management policy and practice of the SADF be able to meet the needs of the organisation and its members in the year 2000?"

A superficial examination of the literature dealing with the predicted and existing changes occurring in the power-bases in the world, the characteristics of successful (ie effective and efficient) organisations, and an assessment of the success of the SADF as an organisation, indicate that the apparent problem may not be the real issue to be addressed.

\section{PREDICTED AND EXISTING CHANGES}

Much has been written about the future, and many a prophet has had to hang his head in shame or quickly find a plausible explanation for his failure to predict changes and disasters in time. Crystal-ball gazing is a hazardous occupation at the best of times, and the prediction of the occurrence of actual events even more so. The creation of plausible scenarios and the identification and interpretation of trends so that appropriate correcting action can be taken, is at least feasible though.

By way of illustration certain changes which have or could have visible effects on the SADF are highlighted in the following paragraphs. 


\section{Accelerating Rate of Change}

This country, indeed the world, is in a state of change. The fact of change is generally appreciated, but the fact that the rate of change is increasing (or accelerating) is not generally realised.

Perhaps closer consideration of certain everyday occurrences will serve to illustrate this problem.

Only a few years ago it was possible to take a year to teach a young soldier, sailor or airman the rudiments of his trade, knowing that those skills would last him for his entire career. Today, more than was taught that young man in a year is propped into a few short months, and used very effectively in battle. What is frightening though is that very few of the skills taught to us a few decades ago are valid today. Knowledge and skills are changing so quickly and increasing in volume so rapidly that, for example, an engineer can be out of date once he has completed his degree.

This accelerating change has a number of sideeffects. Too-rapid change brings about it instability, impermanence, a feeling of transience and stress (Toffler, 1970: 238). Outwardly people may not change, but in their behaviour towards others, the attitudes to their jobs and the environment, they do change and these changes can be distressing to all.

\section{Demographic Change}

The basic facts of South Africa's demographic situation are well-documented (Gerber, Nel and Van Dyk, 1987: 31 et seq) and reveal that:

(a) The white population which (like its American and European counterparts) has a lowbirth-rate, will form a smaller percentage of the total population in future.

(b) The "coloured" and Indian population groups have a higher growth rate than the whites, and will form a slightly larger percentage of the population of the future than they do at present.

(c) The black population will form a significantly larger percentage of the total population by the year 2000 .

Expressed in terms of statistics, some other interesting changes begin to emerge. The total population of the Republic will grow from approximately 32,1 million in 1985 to approximately
44,8 million in the year 2000 . The black population will provide about 11,1 million of this growth, while the remaining 1,6 million will come from the remaining population groups, to make up the growth of approximately 12,6 million. Significantly, the white population will "age" while the black group will become younger. At present less than $27 \%$ of the whites are younger than 15 years of age, and approximately $8 \%$ are over 65 . By the year 2000 this ratio will change to $20 \%$ and $10 \%$ respectively. Amongst the black population, $43 \%$ are presently younger than 15 and only $3 \%$ older than 65 years. By the year 2000 , $39 \%$ will still be under 15 and there will still be only $3 \%$ older than 65 .

If one considers that a large proportion of the managerial, executive and clerical jobs presently require a degree or diploma qualification, then a predicted shortage of 65000 graduates and 37000 diplomates is a cause for concern. More concern is needed when one considers that there will be a surplus of more than 3 million in the educational category Std 8-10 (Ibid:41). The majority of these matriculants will be academically-trained in a world demanding an increasing number of technically-skilled workers. Such an imbalance is bound to place more strain on the already heavily-burdened leader group, with consequence adverse effects on performance and so on.

The SADF has already began to absorb larger numbers of the black, "coloured" and Indian population groups into the structure. Because of the differences in culture and outlook between the various groups and the existing membership of the SADF, changes largely undefined as yet, will need to be made to the SADF. If one accepts that the greater number of those who join the SADF in the future will be of the Third World, while the SADF is essentially First World in nature, provision will need to be made for major cultural adjustments in one direction or another.

\section{Technological Change}

Technology may be defined as that amount of information and/or skills and experience developed for the production and utilisation of goods and services. It may include the following:

(a) Scientific and technical knowledge

(b) Engineering knowledge

(c) Managerial knowledge

used in the speficiation, design, development 
and application of the technology (Australian Government, 1980: 3).

Technological change is, therefore, change in the technology (the processes, materials, machinery or equipment) which has an effect on the way the work is performed. This change also affects the people in the organisation.

The SADF has been involved in a war in which highly-sophisticated technology (hi-tech) plays a major part. Some of the equipments ranged against us in the past (and, in all likelihood, in the future) were so new and advanced, that the military people of the West had not yet had experience of them. Such hi-tech equipment calls for high levels of (especially) technical education for its development and maintenance, while lesser skills may be demanded for its operation.

Significantly, the greater portion of the skilled designers and maintainers come from the white population, and a very small portion from the black population (Ibid:34) with no predicted change coming.

The increasing sophistication of the weaponry needed to survive will demand higher and higher skills of the maintainers of the equipment, whose skills will become more and more essential. At the same time, economic development in the country, also essential for survival, together with technological change will place even greater demands on the very limited skilled manpower available. In some ways, this need will have to be met, in a very short time, from the other population groups.

The changes occurring, and the resulting pressures and demands on employees, will cause them to react in different ways. They seem to react to these increasing demands and pressures in one of two ways: either they accept the situation as a challenge and rise to it, or they see it as a threat and tend to avoid or resist the change (Gerber, Nel and Van Dyk, 1987: 80). The adaptation or otherwise of the individual will be determined largely by the nature of the psychological contract, entered into between him and the organisation (Ibid: 84).

\section{Change in Attachment to and involvement with the Organisation}

An accepted norm among the majority of longserving members of the SADF is long-term attachment to the organisation (career-orientation, or long-service) and involvement with or commitment to the aims and objectives of the SADF (loyalty).

It is becoming increasingly evident that a large proportion of the younger members (and potential members) do not subscribe to either of these norms. Occupational mobility has grown to the extent that five to six different jobs in different organisations in a working lifetime, is the norm (Toffler, 1970: 106). This "serial-career pattern" has significant implications for an organisation whose entire administration pattern and reward system is based on long-service.

Of further significance is the growing tendency of the individual to be loyal to his own needs and desires, and not to the aims and needs of the organisation, unless these happen to coincide. The individual increasingly is committed to his job (and not the organisation) only as long as it meets his needs. When it no longer does, he will move to where his needs are met, albeit only temporarily.

Since the member's behaviour can be seen as a function of his perception of the content of the psychological contract he entered into with the organisation, a review of this contract in the light of the perceived needs of present and future members of the SADF is called for (Gerber, Nel and van Dyk, 1987: 121).

\section{Change in Personal Needs and Occupational Commitment}

The ease and frequency with which persons can move from one end of the country to the other is generally appreciated. Such mobility is essential to meet the increasing demands made upon the limited time of skilled personnel. In the SADF, it is also accepted practice that for personal growth and development of the leader group. relatively frequent re-appointment and posting to different jobs and geographical areas is necessary.

However, more and more families are becoming two-job families ie both husband and wife work at a paying job. Both partners working for economic reasons is a well-known situation; the new trend among the more highly-developed groups however is for the wife to work in order to satisfy her personal needs and desires. This coupled to the change in attachment to the organisation, and a need for stability to counter the instability caused by accelerating change, has led to an 
increasing reluctance on the part of members of the private sector to move home on demand. Such members prefer to sacrifice the advantages accompanying the move for the stability and comfort of remaining in an area and job which meets their personal needs and their preferred life-style. This has in turn led to a number of the so-called "commuter marriages" where the one member commutes weekly or so to the family home, spending the remainder of the time at or near the work-place. While not yet prevalent in the SADF, isolated cases have been reported.

\section{Productivity}

South Africa is known for a relatively low level of productivity, and several programmes for improving such productivity are on the go now. especially in the SADF. While not decrying the need for programmes to improve productivity, one needs only to look at the total activity pattern of any person to wonder whether productivity really is low. The emphasis on total activity pattern is deliberate for, while the individual might work at only a $66 \%$ rate at his job during the official work day, a study of his other acitivities might be revealing. Many members of the SADF belong, for instance to private, professional, church and charitable organisations; actively participate in sport or the administration of sport: and an unknown number have paying hobbies. It is quite probable that the individual works harder and more productively at these activities than he does at his job. He might well be expending more energy on the achievement of these tertiary objectives than on his primary or job objectives. The answer to the question "Why?" might provide managers with great insight into the reasons why people work.

Among some population groups, the need to work ends when sufficient funds have been earned to satisfy an immediate need. Then the individual simply stays away from work until the need for more money arises. The effect of this attitude on an organisation committed to regular working hours and pre-planned activities can be hilarious if not disastrous!

Perhaps from this simple example a principle can be derived: Man works productively as long as his needs are capable of being satisfied by his work. If man, tied to his work (by convention, contract or whatever), is dissatisfied and cannot leave it, he satisfies his needs in other ways.

The key to success surely lies in identifying the individual's needs and directing them so as to meet the objectives of the organisation and the needs of the individual.

The individual's motivation to work has changed, or is in the process of changing but in many cases the skills of his manager and the ability of the organisation to provide motivation which counters or accommodates this change have not. By way of example: a young officer might have a need to participate in the decision-making process in order to deliver of his best. Placed under an autocratic leader with no concept of this need or how to satisfy it, the subordinate would almost certainly not be used optimally.

\section{Change in Organisational Structure and Design}

"An armed force is a body of men organised to achieve its ends irresistibly by coordinated action" (Downey, 1977: 62). Cohesion and the need for good organisation are so demanding that the armed forces of the world have often been in the forefront of developements in organisational science.

The multiplicity of roles for which an armed force is compelled to cater for, is reflected in the organisation structure. In the SADF for example apart from preparing for conventional warfare of land, in the air and at sea, counter-revolutionary warfare, action in support of the SA Police, aid in case of civil disaster and so on; are ongoing actions needing a organisation which is exceptionally strong but nevertheless flexible.

Over the decades an organisation structure has evolved which is both functional and modular in design. This is directed towards the man in the front line in order to motivate, train, equip, and direct him and his actions (Downey, 1977: 66).

In the SADF these principles have been applied to develop an organisation dependent upon geographical integrity and unity of command for its effectiveness. In the past decade major changes were made to the organisation, in response to changing needs. A functional (sixlegged) organisation was adopted although in certain fields (notably the Corps directorates of the SA Army), a geographic structure was super-imposed. This structure in itself is gradually being phased out as its functions are taken over by other parts of the organisation.

In the SA Navy, for example a Matrix organisa- 
tion evolved. In a matrix organisation, lines of command, authority and responsibility become blurred, controlled and remain difficult. Several steps have been taken deliberately to simplify the organisation and so solve these problems. The geographical re-organisation of the SA Navy is an example of this.

Whilst under the command of a previous Chief of the SA Defence Force, a move was made towards more participative management, and the development of synergism in management. The then existing organisation was apparently still too inflexible, and there emerged a tendency to appoint "work groups", multi-disciplinary and multi-arm-of-service groups to tackle specific projects or problems. This tendency is typical of the move from a fixed bureaucratic structure to an "ad-hocracy", a flexible temporary organisation whose peripheral structure and composition changes according to the needs of the moment, while retaining a relatively stable core suited to the purpose of the organisation (Toffler, 1970: 120).

\section{Changes in Organisational Culture}

While the concept of organisational culture is difficult to define, it is generally accepted that such a thing exists. In all organisations there are deep-set ideas and beliefs about the way an organisation should be structured, the way people should be led and managed, the way authority should be exercised, the way people should be rewarded and disciplined, the way they should dress and act, the terminology (or language) used and so on. These things make up the culture of the organisation. It reflects a pervasive feeling of life, or a set of norms (Schmikl, 1988: 65). The overall culture of the SADF can be seen as being a "Role Culture", characterised by:

(a) Bureaucratic approach.

(b) Logic and rational basis of decision-making

(c) Organisation structure based on functional specialisations.

(d) Control by procedures; job descriptions; authority definitions; key performance areas; procedures for communications; rules for the settlement of disputes etc.

(e) Coordination at the top by a narrow band of senior managers.

(f) Individuals selected for satisfactory performance of a role. This includes a number of people that can fill or fit the role. Performance over and above the job description is not required and can be disruptive at times.

(g) Innovative ability not fully expoited or realised (Schmikl, 1988: 70).

Culture also reflects the real psychological contract between the individual and the organisation. This is the way that the psychological contract is put into practice. It is here that the individual perceives his satisfaction or otherwise with the organisation.

An organisation's culture (especially that of a large organisation with a long history) changes only slowly. Culture change is a related to the leadership of the organisation. As the leadership projects its own assumptions about the cultural norms and embeds them gradually and consistently in the purpose, structures, objectives and working procedures of the organisation, so the culture will change (Schein, 1987: 317). Some leaders fail to affect (to change or to reinforce) the culture of the organisation because of an inability to visualise the change needed and an inability to articulate and enforce it, because change occurs so slowly, the leadership must be persistent and patient as well in order to effect change.

In the private sector from whence the bulk of SADF personnel comes (ie the National Servicemen and Citizen Force personnel), changes in the culture of organisations and the values of individuals apparently have been taking place more rapidly than in the SADF. This more rapid change has occurred for a variety of reasons including the relative lack of size of a number of the organisations. These changes have affected the expectations and needs of individuals involved with them, and these changes together with the changes taking place in society in general, have brought people with certain cultural norms to the SADF. Where these cultural values differ from those of the SADF, and are not changed to meet those of the SADF, conflict occurs. Resignation or disciplinary problems may be manifestations of this conflict.

Such conflicts of culture and values have adverse effects on the effectiveness and efficiency of the SADF. These conflicts divert attention and effort from achieving the primary objectives of the SADF to resolving the conflicts instead. The question arises whether the culture of the SADF and the sub-cultures in the various Arms of Service, and the values held dear to these organisations are still valid today. If indeed they are, then perhaps more effort needs to be directed to 
changing the cultures and values of entrants to the SADF. If they are not, then perhaps the culture and values of the SADF need to be altered to suit the changing times. Whatever the case may be, the effects of such conflicts on the effectiveness and efficiency of the SADF, illustrate the need to examine the culture, and perhaps change it accordingly.

\section{Change in Leadership Style and Management Philosophy}

Leadership style is seen as being the way in which the management philosophy is applied in practice (Gerber, Nel and Van Dyk, 1987: 100). This has an important impact on the motivation, commitment, adaptability and satisfaction of employees.

Literature on the subject boasts a wide variety of approaches to leadership, or a classification based on the theory applicable to a particular style of leadership. Schilbach (1983: 183) concludes that the situational approach to leadership propagated by Hersey and Blanchard, is the most useful to explain effective leadership. The situational approach is seen to be particularly useful in the complex environment of South African enterprises for the very reason that it is so flexible. The SADF has advocated the application of the situational approach since 1976.

In recent years much has been said about the participation of employees in the decision-making process (Hersey and Blanchard's S3 Style). Some research indicates that:

"employee participation in decision-making in a democratic atmosphere created by permissive leadership, facilitates the development of internalised motivation, and serves to raise the levels of the employee production and morale" (Viteles, in Tiffin and McCormick, 1968: 393).

\section{CHARACTERISTICS OF A SUCCESSFUL ORGANISATION}

Much of the recent literature devoted to organisations emphasises the need for them to grapple with the changes occurring in the external and internal environments and to adapt the organisation to these changes in order to be successful.

The term "successful" is used here to describe an organisation which is both effective and efficient in achieving its objectives (Van Dyk, 1987:
17). This term includes the meaning ascribed to "excellence", a term also popular in the literature (Peter and Waterman, 1982: 8). All the terminology used in the relevant literature has been translated into terms meaningful to the SADF, for the purposes of this paper.

In Appendix A the relationship between three different approaches to the descriptions of the characteristics of a successful organisation are shown.

In their studies of the success of organisations world-wide, Peters and Waterman (1982: 13) and Peters and Austin (1985) identified the following characteristics:

(a) Leadership: The ability to inspire and guide the people in the organisation to the achievement of defined objectives, within a framework of values and culture (Own derivation).

(b) Innovation: In a world of rapid change, it is considered vital to the continued success of the organisation that innovation occur at every level, and not only at some controlled (planning?) point. Again, the reward system needs to be centered upon the need to innovate to survive. An organisation which stifles creative genius will not survive in a changing world.

(c) People Orientation: A standard cliché is that "People are the most important-single factor". There is no denying this fact, but there is also no denying the fact that in most unsuccessful organisations only lip service is paid to this concept. Making people important means identifying their abilities and needs and catering for them in using them to achieve the objectives of the organisation: ie the needs of the individual and the organisation must be made to coincide for success to be achieved.

(d) Objectives: A set of clearly-defined measurable objectives, indicating to all levels of the organisation the short-, medium-, and longterm results that the organisation is committed to achieve.

(e) Commitment: The achievement of success requires the commitment of everyone in the organisation to the objectives of the organisation. This commitment implies the development and embracing of a set of values and rewards totally devoted to ensuring that the interest of the end-user of the product or service remain paramount. It also implies the development of a norm of superior per- 
formance (whether this be service or combat) within the cultural framework, exemplified by all levels of the organisation.

(f) Action Orientation: A bias for action, for getting on with the job. The concept is based on quick, innovative planning followed by implementation rather than lengthy studies followed by bulky reports that are processed by committees. Probably more easily seen as "Boer maak 'n plan", or "getting quick results". The essence though is that the follow-up makes use of research details to confirm the decision and to make any changes that are necessary.

(g) Culture and value based: The culture of the organisation propagates as its norms and values the characteristics described here. The culture and values form the basis of every action taken at every level of the organisation. The value of leadership in forming the culture has been discussed, but can be emphasised here.

(h) Simple organisation, lean staff, decentralised execution: The underlying structural forms and systems are simple, top-level staffs are few, and there is a fanatic insistence upon execution at the lowest level. Autonomy of execution is the rule rather than the exception.

In a study executed for the development of an organisational strategy for the SA Navy, Van Dyk (1987: 583 et seq) defined organisational success in terms of the successful performance of the individual in a team. His successful organisation demonstrated the following characteristics:

(a) Leadership: As defined by Peters and Waterman.

(b) Objectives: As defined by Peters and Waterman.

(c) Utilisation of the Abilities of the Individual: Can be likened to a combination of "Innovation" and "People Orientation" where the individual is encouraged to take every opportunity in the job situation, to use his abilities and to satisfy his needs, and at the same time people are seen as the primary source of the success of the organisation.

(d) Growth: Related to the previous two aspects, the individual is encouraged to grow and develop in a direction suitable to him and to the organisation; similar to the concept of "Self-actualisation" formulated by Maslow (Tiffin and McCormick, 1968: 342).

(e) Status and Recognition: The existence and application of a reward system which em- phasises the recognition and reward of performance which contributes directly to the achievement of the organisation's objectives. Can be allied to "Action Orientation" and to "Commitment".

(f) Accommodating Organisation Structure: An organisation structure designed specifically to achieve the objectives of the organisaton and to make provision for the factors which elicit successful performance from its members. Similar to the concept of "... decentralised execution".

\section{CHARACTERISTICS OF THE SADF AS AN ORGANISATION}

From the aforementioned study executed for the SA Navy (Van Dyk, 1987), the characteristics of successful organisations listed above, and the known characteristics of the SADF organisation, can be deduced by how the SADF compares with the characteristics of successful organisations as depicted in the previous paragraphs. It must be emphasised that these deductions are tentative, extrapolate the findings without verification, and would need further research for confirmation or rejection. These deductions also reflect the personal opinions of the author and not necessarily the official SADF view.

Leadership: The research shows that in the main subordinates consider the leadership style and ability of leaders at all levels to be acceptable.

Objectives: The research shows that the setting of objectives and the issuing of task-guidelines is successful and provides a firm baseline for the achievement of individual task objectives.

\section{Other aspects}

(a) Intrinsic motivators: Although the aspects related to leadership and objective setting inter alia, which contribute to intrinsic motivation, are generally positive, some of those aspects related to intrinsic motivation (growth, challenge, utilisation of the abilities of the individual and so on), are not. This can have the effect of neutralising the positive aspects.

(b) Extrinsic motivators: In general these aspects (reward system, status and recognition, accommodating organisation system) were found to be negative. This can have a negative influence on motivation, innovation, and achievement motivation. 
(c) Simply, the SADF appears to have positive leadership but a less-than-satisfactory, almost punitive human resources support system. The organisation appears to be a strong bureaucracy (which limits innovation and achievement in certain areas) wherein performance tends to be commensurate with perceived norms and the reward system.

\section{THE PROBLEM AS REDEFINED}

In the light of the information in preceding paragraphs, on the changes occurring and predicted, as well as the findings concerning the characteristics of successful organisations and the situation of the SADF vis-a-vis these, the problem can be redefined as a question:

"Does the SA Defence Force's leadership style and management philosophy, organisation culture, values and skill-level meet the requirements for organisational success and personnel needs as predicted for the year 2000?"

Put in another way, the real problem, and the challenge for the future is to use the positive characteristics to reverse the negative ones, to get:

"A leadership style and management philosophy;

an organisation culture and value-set; and

Human Resource Management competencies

which will lead to success in the year 2000."

\section{THE AIMS OF THE CHIEF OF THE SA DEFENCE FORCE COMPARED TO CHARACTERISTICS}

The Chief of the SADF has set four aims or goals (Afr: "Doelstellings"), which if taken in the right context and applied to an organisation, can be likened to the characteristics of a successful organisation. These are (but not in the usual order):

(a) Effective Management: Relates directly to Leadership and Management, as defined previously, and to aspects such as Objectives; Action Orientation; Innovation; Simple Organisation Structure etc. This is seen as "Doing the right thing right the first time!"

(b) Positive Image: Seen as developing the image, culture and value-set of a winning organisation as perceived internally and externally.

(c) High Morale: Can be compared to People Orientation as defined previously.

(d) To win the war: (The prime aim) Seen not just as physically winning any war (or other activity) in which the SADF might be engaged, but also as creating a culture devoted to winning, and as Commitment.

The similarity to the solution of the problem is obvious!

Used as the basis for leadership and management development, organisation and culture change, the development of a set of values and an attitude of mind, and the development of human resource management competencies, these goals point the way ahead for the development of the SADF of the future.

\section{OBJECTIVES OF A SOLUTION TO THE PROBLEM}

From the problem statement, the following objectives can be set, against which the probability of success of a proposed solution to the redefined problem can be measured:

(a) "To define and develop a SA Defence Force leadership style and management philosophy, and an organisation culture and valueset which will lead to success (effectiveness and efficiency) in the year 2000."

(b) "To define and develop in SA Defence Force personnel the human resource management skills, knowledge and attitudes which will lead to successful human resource management in the year 2000."

\section{CONSTRAINTS ACTING UPON A SOLUTION TO THE PROBLEM}

In generating alternative solutions to the restated problem, the following constraints limiting the solutions must be borne in mind:

(a) Top management support: Any solution, to be successful, must be supported actively by top-management, and must permeate the entire organisation. By active support is meant, not only verbal or mental acquiescence, but also the conviction that the solution offered is the only acceptable one and actively striving in a committed manner to make the achievement possible.

(b) Results oriented: The present top-manage- 
ment of the SADF is, by-and-large, of pragmatic disposition and does not take kindly to theoretical or esoteric dissertations which are difficult to associate with the goals of the Chief of the SADF, or are difficult to perceive in terms of short-term operationally-viable solutions. Results are what count.

(c) Culturally acceptable: The SADF has a distinct culture-language which, although somewhat adulterated by misuse and the addition of non-cultural slang, attaches distinct meanings to certain words. The use of so-called "civilian" theories and terms as part of a solution is likely to be rejected. The use of terms such as "management" and "corporate strategy" are examples of unacceptable practice.

(d) Future orientation: Any solution must be aimed not only at the present level of topmanagement of the SADF but also the next generation and the equivalent in the Warrant Officer and Non-commissioned Officer structure.

(e) Negative $O D$ indications: Organisation Development has not the best of success records in the SADF. A "pure" Organisation Development strategy is likely to be seen to fall in the category of "theoretical and esoteric" and "unsuccessful" and is likely to be rejected.

\begin{tabular}{|l|}
\hline SCAN EXTERNAL ENVIRONMENT \\
Socio-political change \\
Demographic change \\
Technological change \\
Economic change \\
National Manpower Policy \\
Labour market conditions \\
Trade Union development \\
Educational development \\
Military situation \\
\hline \\
\hline SCAN INTERNAL ENVIRONMENT \\
Job Content Environment \\
Nature of work \\
Task guidelines, aims and objectives \\
Utilisation \\
Status and recognition \\
Development \\
Job Context Environment \\
Organisation structure and type \\
Organisational culture \\
Management philosophy \\
Leadership style \\
Personnel philosophy and policy \\
Working conditions \\
Interpersonal and group relations Manpower/Manning \\
Policy \\
\hline IDENTIFY PSYCHOLOGICAL CONTRACTS \\
\hline Individual \\
Organisation \\
\hline IDENTIFY MEMBER CHARACTERISTICS AND EFFECTS \\
Personal environment \\
Culture \\
Education \\
Needs \\
Experience \\
Training \\
Skills and knowledge \\
Attitude to military service \\
Political attitude \\
Psychological characteristics \\
\hline
\end{tabular}

INTEGRATE AND DEVELOP SCENARIOS FOR FUTURE Determine strategic concerns and key decisions parameters

dentify key environmental forces Define scenario logics Evaluate scenarios, implications and action Evaluate scenarios, Discuss scenarios etc top management

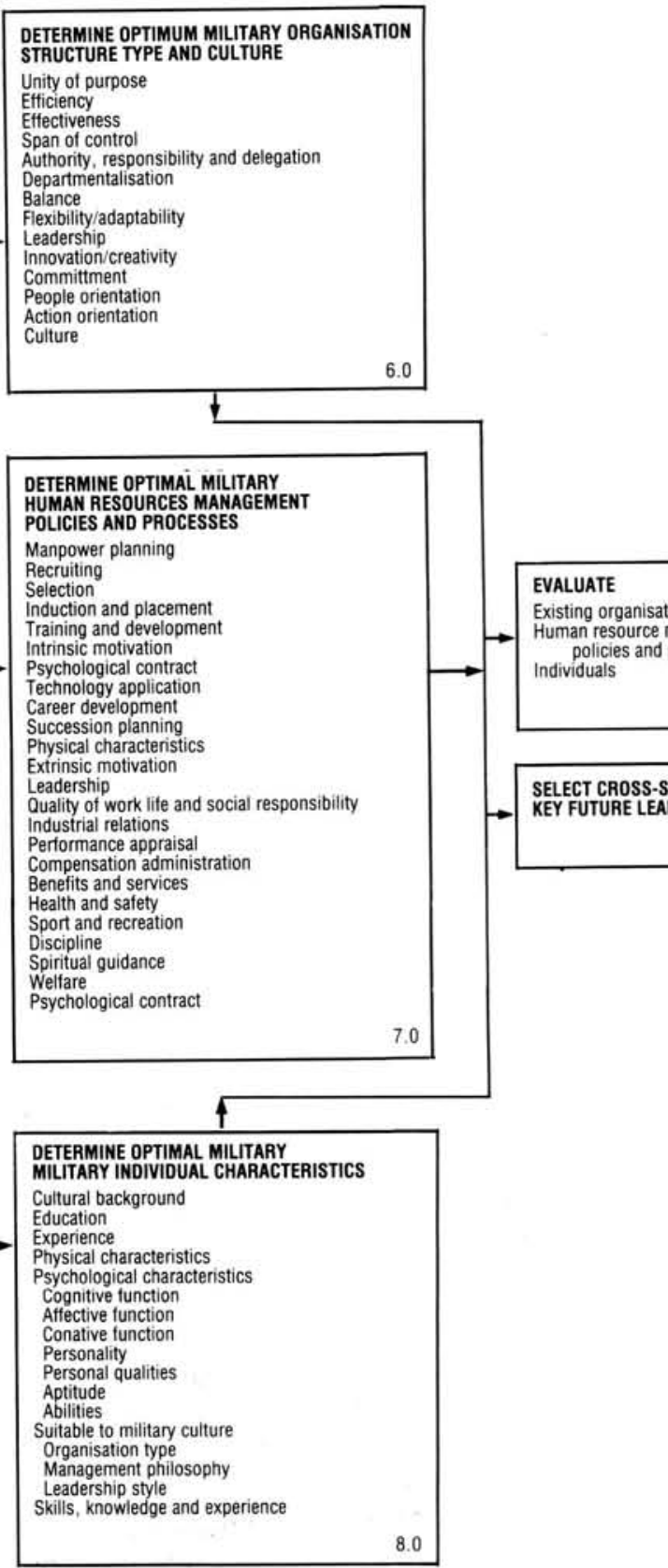


(f) Prescriptive rather than descriptive: A solution framed in terms of prescriptive actions and regulations is more likely to be implemented than a philosphy.

(g) Use training strength: The SADF has a strong positive bias towards training and development programmes, and a solution which can be implemented via such a programme is more likely to be accepted than a philosophy.

(h) Hi-tech need: Despite the recent influences of other cultures, the SADF culture is largely of First World nature, while large numbers of future personnel are likely to be of the Third World culture and value system. As the recent war in which the Republic was involved demanded First World technology (hi-tech), any solution must take into account the need to develop or establish a First World culture and value system in the new entrants, or reach an effective compromise.

(i) Financial limitations: Strict financial restraints are likely to be placed on any solution offered, due to the restricted SADF budget.

(j) Changing composition of work-force: The change in the population composition of the Republic and the commensurate problems of education make it likely that future entrants will be selected from the matriculant groups and those of lower educational levels, as indicated in the SADF Long-term Manpower Forecast. This composition could have an effect on the type and level of developmental courses offered.

(k) Leader selection: Selection and development of future leaders will need to take into account their ability to lead in a climate of ambiquity and change, and their ability to function at the high cognitive level required by this and the high complexity of the future.

(I) Integrated implementation: Any solution must take cognisance of and be integrated with the:

(i) National aims and objectives.

(ii) National manpower plan.

(iii) National Military manpower plan and the need for the development of subsidiary plans covering:

- SA Defence Force Development Plan. - SA Defence Force Manpower Plan.

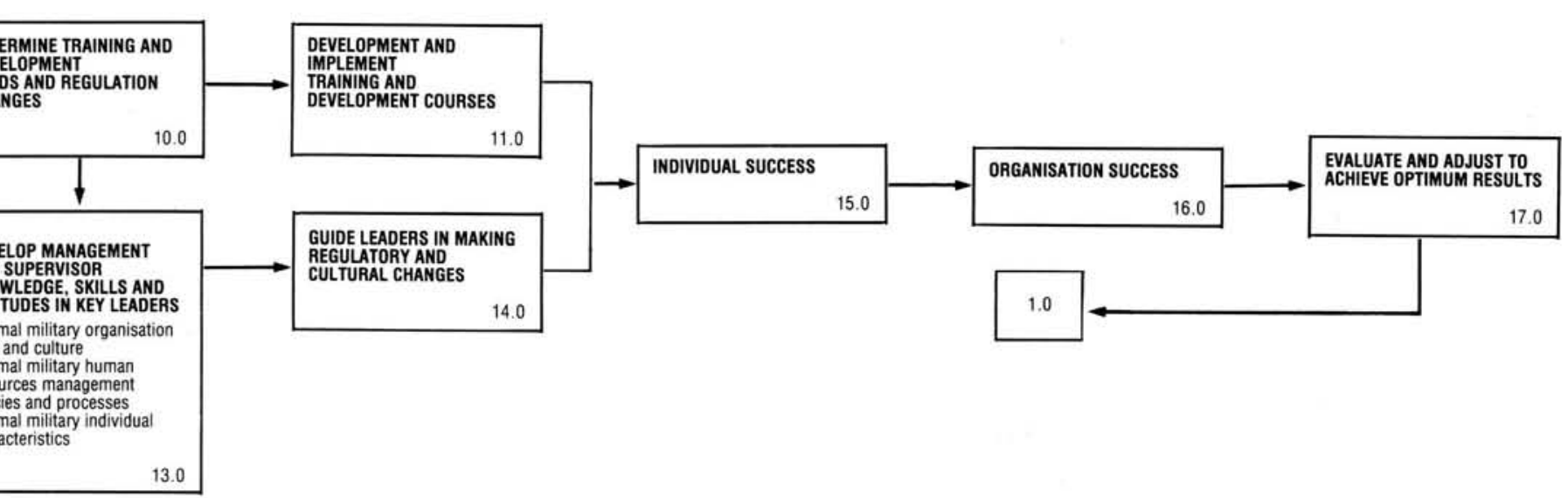




\section{PROPOSED PLAN OF ACTION FOR DEVELOPING THE HUMAN RESOURCES OF THE SA DEFENCE FORCE FOR THE YEAR 2000}

Table 1 is a diagramatic representation of the steps considered necessary to execute an action plan for human resource development in the SADF of the year 2000. This action flow diagram is a representation of the systems approach, and depicts the action at the first level of detail. Each of the blocks (1.0; 2.0 etc) can be analysed into greater detail as the plan develops. The lines joining the various blocks have the direction of action flow shown by the position of the arrow near the junction of the lines. The final arrow at block 17.0 indicates the start of a feedback and evaluation loop, requiring the next action to be taken at block 1.0 ie the start of the system.

Table 1 also represents diagrammatically, the implementation of the recommended solution; the combination of Alternatives 2 and 3. Each block (or Step) in the action plan can now be discussed.

\section{Step 1:0: CONDUCT EXTERNAL ENVIRONMENTAL SCAN}

(a) Environmental scanning is a procedure whereby information is gathered as input to scenarios which in turn provide strategic direction and a long-term context for planning. Scanning therefore is future-oriented. It attempts to divine something of the future for the present trends. Environmental scanning can progress through four phases, starting with wide panoramic "undirected" viewing, gradually narrowing the focus of scanning until a formal search of relevant information is carried out. (Auguilar, 1967).

(b) The areas listed in Step 1.0 represent the areas for formal search. These are areas known to impinge upon the human resource of an organisation (Gerber, Nel and Van Dyk, 1987: 91).

\section{Step 2:0: CONDUCT INTERNAL ENVIRONMENTAL SCAN}

(a) In a similar way, an internal environmental scan is conducted. The internal environment is that within which the individual member of an organisation works. It can be divided into two areas: the job content environment, and the job context environment.

(b) The job content environmental scan ad- dresses matters such as what is done; how it is supposed to be done; how well the skills and knowledge of the individual are utilised; what status he enjoys as a result of the job; what recognition is granted; and whether the job provides opportunities for development and growth.

(c) Scanning the job context environment involves an examination of the organisation structure, type and its culture. The latter is of prime importance when one is considering change in the organisation (Schein, 1987: 244). Also to be examined are the management philosophy, the leadership style, the personnel philosophy, the working conditions and the interpersonal and intergroup relations, all of these aspects affect the functioning of an individual in the organisation (Gerber, Nel and Van Dyk, 1987: 94).

\section{Step 3.0: IDENTIFY MEMBER} CHARACTERISTICS AND EFFECTS

(a) As the entire action programme is centred upon the individual member of the SADF a study of the individual and the effects of certain parameters upon him and of future changes in these parameters upon him is an essential step.

(b) Aspects requiring examination include, but are not limited to, the envirorment within which the individual grows up, including his immediate family environment; the culture to which he is exposed; and his educational experiences. Of particular value in our changing country is the attitude he holds to the military, and to the political developments occurring.

\section{Step 4.0: IDENTIFY PSYCHOLOGICAL CONTRACTS}

(a) Before an individual joins an organisation, a form of psychological negotiation takes place between the individual and the organisation. This "negotiation" may actually take place or else it may be assumed by both individual and organisation. The resulting "psychological contract" contains the individual's expectations and his personal objectives. In turn, the organisation indicates what it expects from the individual, and its objectives (Ibid: 94 ).

(b) Unrealistic present and future expectations can lead to conflict between the organisation, which can lead to restrictive work practices, low morale and even to a parting of the ways. 


\section{Step 5.0: INTEGRATE AND DEVELOP SCENARIOS FOR FUTURE}

(a) It is unlikely that a single forecast or prediction of events could contain the complexity and uncertainty of the long-term future. A scenario is used to present decision-makers with a "fan" of possible and probable futures, enabling them to take more factors into account when planning future action programmes. Scenarios are, however, hypothetical, the future cannot be predicted by using the current methods of science. The best that can be done is to outline the images of the future that is emerging.

(b) It is possible to identify five stages in scenario development, namely:

(i) Identify strategic concerns and key decison-making parameters.

(ii) Identify and analyse key environmental forces.

(iii) Define scenario logic.

(iv) Elaborate scenarios.

(v) Communicate scenarios to senior management and outline alternative action programmes for the organisation.

(c) From this step it is hoped that it will be possible to highlight those key aspects which are likely to affect the human resources of the SADF of the future, and to indicate the adaptations necessary to control and direct as far as possible, those aspects to the advantage of the organisation and of the individual members of the organisation.

\section{Step 6.0: DETERMINE OPTIMUM MILITARY ORGANISATION STRUCTURE TYPE AND CULTURE}

(a) Organisation structure is capable of serving many functions at the same time, but incapable of serving all functions equally well all the time. The optimum type of organisation structure for any organisation is therefore the one which most nearly serves its needs and at the same time enables it to meet its objectives.

(b) The earlier examination of the characteristics of successful organisations provides some of the characteristics against which an organisation can be assessed for future suitability. In summary these characteristics are:

Unity of purpose

Efficiency

Effectiveness

Span of control
Authority, responsibility, and delegation

Departmentalisation

Balance

Flexibility/adaptability

Leadership

Innovation/creativity

Commitment

People orientation

Action orientation

Culture

(Peters and Waterman, 1982: 13)

(Peters and Austin, 1985: 5)

(Koontz I'Donnel, 1976: 429

(Gerber, Nel and Van Dyk, 1987, 201)

(c) An evaluation of the present organisation against the future needs and the scenarios, based on these characteristics, should indicate the direction for future development of the organisation structure, or confirm the suitability of the existing one.

\section{Step 7.0: DETERMINE OPTIMAL MILITARY HUMAN RESOURCES MANAGE- MENT POLICIES AND PROCESSES}

(a) In the same way, an examination of the present human resource management policies and processes in the light of the scenarios, should provide the basis for confirmation or adjustment of them.

(b) The list of items is based on the commonly accepted elements of the personnel function (Gerber, Nel and Van Dyk, 1987: 126 et seq) with those aspects peculiar to the SADF personnel function (such as Sport and Recreation, Discipline, Spiritual Guidance and Welfare) included.

(c) An optimum array of human resource management princples, policies and processes applicable to the military situation is the hoped-for end result.

\section{Step 8.0: DETERMINE OPTIMAL MILITARY INDIVIDUAL CHARACTERISTICS}

(a) The SADF has essentially two sources of manpower, viz those who have a military service obligation, and those who volunteer for "Permanent" service ie the so-called "career militarists". The former have no choice about serving, the latter do have. The needs, desires and attitudes to service of the former may well differ from those of the latter, but both need to be accommodated in the organisation if the SA Defence Force is to retain its character as a "national" (Afr: "volks") defence force.

(b) It is accepted though, that only a limited 
percentage of the population have a desire for a career in the armed forces. This analysis and prediction endeavours to identify the "ideal" career militarists, and to distinguish them from obligatory service persons. This information can then be used in the recruiting, selection, training and development of both groups to the optimum. It can also be put to use in the refining of the human resource management policies and processes, and in the adjustment of the occupational groupings or jobs according to the inherent capabilities of the manpower source.

\section{Step 9.0: EVALUATE}

Although this step is separated from the foregoing, the nature of the exercise is such that information gathered will be evaluated as it is gathered. This step is meant to ensure and confirm that the evaluations made are indeed valid, before proceeding to the next step.

\section{Step 10.0: DETERMINE TRAINING AND DEVELOPMENT NEEDS AND REGULATION CHANGES}

(a) Much is said in few words. This step is one of the keys to the success of the action plan. It is assumed that from the foregoing analyses, certain differences and defects will be found in primarily the organisation structure, culture and in the regulations and processes controlling the application of the human resources.

(b) This step aims at translating those into training and development needs (expressed in terms of knowledge, skills and attitudes) and into changes in regulations. It must be evident though, that a large body of manpower schooled in the theories and principles underlying these needs and regulation changes is needed to perform this translation. Without the essential background, the necessary changes and adaptations will not even be recognised, let alone translated into practice.

\section{Step 11.0: DEVELOP AND IMPLEMENT TRAINING AND DEVELOPMENT COURSES}

(a) In pursuance of the concept that the SA Defence Force will willingly accept training and development courses, and changes to the regulations, the characteristics of a successful military organisation and successful military human resource management policies and processes etc are translated into courses and regulations, which are then developed using the normal SADF practice. In this development due cognisance must be given to modern mass-training methods.

\section{Step 12.0: SELECT CROSS-SECTION OF KEY FUTURE LEADERS}

(a) The source of this large body of manpower, is a cross-section of the key future leaders of the SADF. Essentially the implementation of a large-scale succession plan, the identification of key leaders at all levels in the organisation, is a vital step in the action plan.

(b) These leaders, who should represent all the potential future top personnel in the SADF (both in the officer and the rating structure) should themselves be shaped (given the necessary knowledge, skills and attitudes) so that they can in turn shape the SADF to cope with the future ie they are given the opportunity under the guidance of the Chief of the SADF and the top structure to create the successful defence force of the future.

(c) These key leaders are placed in posts (or on ad hoc committees) where they are in a position to train, develop and influence their peers and subordinates, and assist in creating the optimum situation.

\section{Step 13.0: DEVELOP MANAGEMENT AND SUPERVISOR KNOWLEDGE, SKILLS AND ATTITUDES IN KEY LEADERS}

(a) To achieve real and lasting changes in organisation structure, policies and processes it is essential that the organisation culture adapts to and supports those changes. Cultural change in itself is a complex and longterm process requiring skilled intervention to achieve.

(b) By providing the key leaders with the essential leadership, managerial and supervisory knowledge, skills and attitudes in the area of organisation structure, culture, human resources management, and personnel training and development, the stage is set for the institution of incremental changes to the organisation.

\section{Step 14.0: GUIDE LEADERS IN MAKING REGULATORY AND CULTURAL CHANGES}

(a) Great as the temptation may be to believe 
that changes as great as those implied by this action plan may be made overnight, or by radical action, it is vital that it be understood that the training, developmental, regulatory and cultural changes advocated cannot be achieved overnight.

(b) A change of this magnitude, especially where culture change is involved may take between 6 and 15 years! (Scholz, 1987: 175).

(c) Such change which must be lead by the Chief of the SADF and his top management, must be incremental. The role of the leaders in this process is:

(i) To communicate the new vision of the future throughout the organisation;

(ii) To mobilise the commitment of the whole organisation towards achieving the new vision; and

(iii) Systematically institutionalise the changes into the organisation (Tichy and Ulrich, 1984: 59) using the key leaders chosen and developed for this role.

(d) The process of incremental change has four characteristics, viz:

(i) Reform starts by top management developing a new vision or perspective of the most likely conditions or scenarios for the future

(ii) The reforms are implemented by systematic changes in the human resources sub-systems, each sub-system requiring a somewhat different set of actions, information needs, and timing requirements.

(iii) Change is kept incremental by commencing with broad, vague steps, gradually refining the steps as the necessary information becomes availble.

(iv) One error in making change, is that the changes are frozen or fixed too soon, and then require unfreezing and reorientation or re-doing. It may be necessary to make major changes to the human resource management policies and processes of the SADF using innovative thinking and methods. It is logical to assume that too much change too soon, will meet with great resistance and is likely to fail. Caution, patience and innovation is needed.

\section{Step 15.0: INDIVIDUAL SUCCESS}

(a) Individual success comprises two compo- nents, viz: individual effectiveness and individual efficiency (Gerber, Nel and Van Dyk, 1987: 433)

(b) Individual efficiency refers to the input, throughput and output of the individual within the context of job, job content, and the environment within which he functions. Individual effectiveness means the extent to which the individual "does the right things", and is also affected by the same factors.

(c) To ensure individual success the organisation has to ensure an acceptable "degree of fit" between the individual and the following variables:

- the nature of the job

- task guidelines and objectives

- the utilisation of the individual

- his status and recognition

- his development

- the organisational culture

- the management philosophy

- leadership style

- personnel policy

- working conditions

- intergroup and group relations

- availability of the technology needed to do the job (Ibid: 93)

(d) Providing the basis for individual success, has been the objective of the entire human resources management action plan just described. Given success there, individual success should follow naturally. Ensuring individual success is largely dependent upon the application of sound human resources management principles.

\section{Step 16.0: ORGANISATION SUCCESS}

The success of an organisation is the result of the interaction of a great number of variables. These include the defining of the mission of the organisation, the setting of objectives, and the provision of resources such as money, materials and men. Resources become useful only through the intervention of the human resources of the organisation. The human resources consist of individuals, groups and management. Provided the individual is successful, the group may be made successful by management, and this should lead naturally to organisation success (Ibid: 18). Should this occur, then the SADF would have achieved the objective set for the Human Resources Development Plan.

\section{RESEARCH REQUIREMENTS}

From the foregoing discussion it is apparent that 
a great deal of research and large resources will be required to make accurate assessment in terms of the various steps in the process. While this is true, such intensive research need not prevent action from being taken in the meantime. In terms of the concept of incremental adjustment, action can be taken based on available information, to be adjusted as more information becomes available from the research sources

For example, detailed research has already been carried out into the selection of leaders for the SA Navy. Such information could be applied to the development of selection tests for the SADF as a whole, and additional research commissioned if necessary. Such research could then be used at a later stage for refinement of the selection procedure.

The need for the creation of a large research organisation could be avoided by calling on existing resources and expertise inside and outside of the SADF. In such a way, results could be obtained in much shorter order than would normally be the case.

\section{COST AND PERSONNEL IMPLICATIONS}

At this early stage of development, no indications can be given of the costs and personnel implications demanded by such a plan of action. Suffice to say that, given the existing resources of the SADF, the existing training management organisation, facilities and load, it is conceivable that a redirection of the effort and the implementation of a more directed succession plan under the guidance of the Chief of the SADF, could feasibly produce the results desired.

\section{CONCLUSION}

In this paper an attempt has been made to present a proposed plan of action to enable the SADF to achieve optimum development and utilisation of its human resources in the year 2000. The apparent problem was stated as being:

"Will the personnel management policy and practice of the SADF be able to meet the needs of the organisation and the people in the year 2000?"

In an attempt to define the real problem more accurately, several factors affecting the personnel situation now and in the future were identified.
An examination was made of the characteristics of successful organisations, and comparisons made between these and the SADF.

On the basis of these findings, the problem given was re-defined as:

"Will the SADF's leadership style and management philosophy, organisation culture, values and skill-levels be able to meet the requirements for organisational success and personnel needs as predicted for the year 2000?"

The objectives for a solution to the problem were then defined as follows:

(a) "To define and develop an SADF leadership style and management philosophy, and an organisation culture and value-set will lead to success (effectiveness and efficiency) in the year 2000"

(b) "To define and develop in SADF personnel the human resource management skills, knowledge and attitudes which will lead to successful human resource management in the year 2000".

Three alternative solutions to the problem were considered in the light of the constraints likely to exist, and it was decided to recommend a plan based upon a combination of developing and implementing regulations and on a training and development programme aimed at providing coping skills to selected key people. In essence the action plan proposed has the following elements:

(a) Scanning the external environment to determine the effects of external factors upon the human resources of the organisation.

(b) Scanning the internal environment relating to job content and context, to identify possible future trends.

(c) Identifying the effects of certain factors upon the individual who is a potential or actual member of the SADF.

(d) Identifying the psychological contracts pertaining to and desired by both individual and the SADF.

(e) Integrating all of this information, and developing from it scenarios for the future, which could provide a range of probable and possible visions of what the future might hold.

(f) Using this information and the results of research and experience to determine the optimum type of organisation structure and culture for the SADF of the future. 
(g) Doing the same with respect to the human resources management policies and processes in the military situation.

(h) Trying to identify, from the information and research available, the characteristics of the individual who would deliver optimum performance in the military milieu.

(i) Evaluating the existing organisation, human resources management policies and processes and the individual against this information to determine the adjustments and corrections needed in order to cope with the future.

(j) Developing from this evaluation the training and development needs and changes to regulations required to form a basis for the development programme.

(k) Developing and implementing the training and development courses needed.

(I) Selecting a cross-section of the key future leaders of the SADF to form the nucleus and catalyst around which the changes and developments could take place, under the guidance of the Chief of the SADF and his top-management team.

(m) Developing in these key leaders the management and supervisory knowledge, skills and attitudes needed to implement the development programme.

(n) Achieving the hoped-for individual success and the concomitant organisational success and achieving the objectives of the of the programme.

(p) Assessing progress made at various stages and making the corrections necessary as the programmes progresses.

Certain key facets which have a critical bearing on the success of the programme were emphasised. These include:

(a) The success of the programme is dependent upon the active support and partici- pation of the Chief of the SADF and his topmanagement team.

(b) The programme can never be a "quick fix". The changes advocated to organisation, value-set, culture and human resources management policies and processes need to be implemented incrementally over a long period of time. Such a programme can take 6 to 15 years to finalise.

(c) It is feasible to suppose that a redirection and re-focussing of the efforts of the training and development organisation and facilities of the SADF would provide the resources needed to implement a programme of this nature.

* Rear-Admiral R. Eberlein S.D. DEd is Chief-Director Manpower Provisioning and Development SADF.

\section{Bibliography}

1. Aguilar, F.J. 1967. Scanning the business environment. Macmillan: New York.

2. Australian Government, 1980. Report of the Committee of Inquiry into Technological Change in Australia, vol. I. 3. Downey, J.C.T. 1977. Management in the Armed Forces. McGraw-Hill:
London.

4. Gerber, P.D., Nel, F.S., and Van Dyk, P.S. 1987. Human Resources Management. Southern Book Publishers: Johannesburg.

5. Koontz, H. and O'Donnel, C. 1976. Management. McGraw-Hill; Kogakusha, Tokyo.

6. Peters, T. and Austin, N. 1985. A Passion for Excellence. Collins: London.

7. Peters, T. and Waterman, R.H. 1982. In Search of Excellence. Harper and Row: New York.

8. Schein, E.H. 1985. Organizational Culture and Leadership. Jossey-Bass, San Francisco.

9. Schilbach, C. 1983. Die ontwikkeling van leierskapvaardighede by middelvlakbestuurders. Unpublished DCom thesis, University of Pretoria.

10. Schotz, C. 1987. Corporate Culture and Strategy - The Problem of Strategic Fit, in Long Range Planning, Vol. 20, No. 4.

11. Schmikl, E. 1988. Establishing an effective and efficient corporate culture. Seminar documentation, University of South Africa.

12. Tichy, N. 1983. The essentials of strategic change management, in the Journal of Business Strategy, 3(4): 55-67.

13. Tiffin, J. and McCormick, E.J. 1968. Industrial Psychology. George Allen and Unwin: London.

14. Toffler, A. 1970. Future Shock. Pan Books: London.

15. Van Dyk, P.S. 1987. Die ontwikkeling van 'n organisasie-ontwikkelingsstrategie vir die SA Vloot. Unpublished DCom thesis, University of
South Africa. 